\title{
A case of oncocytic carcinoma of the endometrium
}

\author{
Hiroshi Kajiwara $\cdot$ Nobue Kumaki $\cdot$ Kenichi Hirabayashi $\cdot$ Masaki Miyazawa \\ Naoya Nakamura · Takeshi Hirasawa - Toshinari Muramatsu • Mikio Mikami · \\ Masanori Yasuda $\cdot$ R. Y. Osamura
}

Received: 16 June 2008 / Accepted: 21 August 2008 / Published online: 9 September 2008

(C) The Author(s) 2008. This article is published with open access at Springerlink.com

\begin{abstract}
We report an unusual case of endometrial adenocarcinoma in a 80-year-old woman who underwent mastectomy for breast cancer at 68 years of age. The tumor diffusely involved the entire thickness of the myometrium. Atypical cells throughout the tumor contained abundant oxiphilic cytoplasm and were arranged in a solid or solidtubular nests in a focal papillary manner. Components of the carcinoma were focally observed in situ. The tumor was classified according to the International Federation of Gynecology and Obstetrics (FIGO) as grade 2 and stage IIIa. Immunohistochemistry revealed that the tumor cells were positive for $\mathrm{p} 53$ but negative for vimentin, estrogen, and progesterone receptors, GCDFP-15, and mammaglobin. They were positive for antimitochondrial antigen and thyroid transcription factor- 1 . The Ki-67 labeling index was approximately $50 \%$. Immunostaining revealed endometrial oncocytic carcinoma. Distinguishing between primary uterine neoplasm and carcinoma caused by metastasis of breast cancer appears important.
\end{abstract}

Keywords Oncocytic carcinoma - Endometrium . Pathology $\cdot$ Immunohistochemistry $\cdot$ Ultrastructure

H. Kajiwara $(\bowtie) \cdot$ N. Kumaki $\cdot$ K. Hirabayashi $\cdot$ M. Miyazawa N. Nakamura $\cdot$ R. Y. Osamura

Department of Pathology, Tokai University School of Medicine, 143 Shimokasuya, Isehara, Kanagawa 259-1193, Japan

e-mail: h-kaji@is.icc.u-tokai.ac.jp

T. Hirasawa $\cdot$ T. Muramatsu $\cdot$ M. Mikami

Department of Obstetrics and Gynecology,

Tokai University School of Medicine,

143 Shimokasuya, Isehara, Kanagawa 259-1193, Japan

M. Yasuda

Department of Pathology, Saitama Medical University International Medical Center, 397-1 Yamane, Hidaka,

Saitama 350-1298, Japan

\section{Introduction}

Pure oncocytic carcinoma of the endometrium is very rare, and few such cases have been reported [1]. Tumor cells possess oncocytic cytoplasm, which contains many mitochondria, as observed in ultrastructural studies [1]. Immunohistochemistry reveals that these tumors are positive for p53 and negative for estrogen receptor (ER) and progesterone receptor $(\operatorname{PgR})$ [1]. The immunostaining pattern in pure oncocytic carcinoma is different from that in common endometrioid adenocarcinoma [2]. Thyroid transcription factor 1 (TTF-1) expression in some endometrial cancers has been recently reported [3]. The breast cancer of this patient was resected 12 years ago. Breast cancers occasionally metastasize to the endometrium [4]. The immunohistochemical profile differs between breast cancers and oncocytic endometrial carcinoma $[1,5]$. Therefore, in this case we could differentiate between endometrial oncocytic carcinoma and endometrial carcinoma metastasized from breast cancer.

\section{Case report}

A 80-year-old woman, gravida 2, para 2, was admitted to the Tokai University Hospital with the chief complaint of genital bleeding. She had a history of breast cancer for the last 12 years, which was resected, following which she underwent postoperative chemotherapy (tamoxifen) for 1 year. The cancer was not recurrent until this episode. Endometrial cancer was suggested by ultrasonography and computed tomography scans. No tumor lesions were detected in other sites, such as the thyroid and adrenal glands. There was no local recurrence of breast cancer. The tumor markers CEA, CA19-9, and CA125 were within 


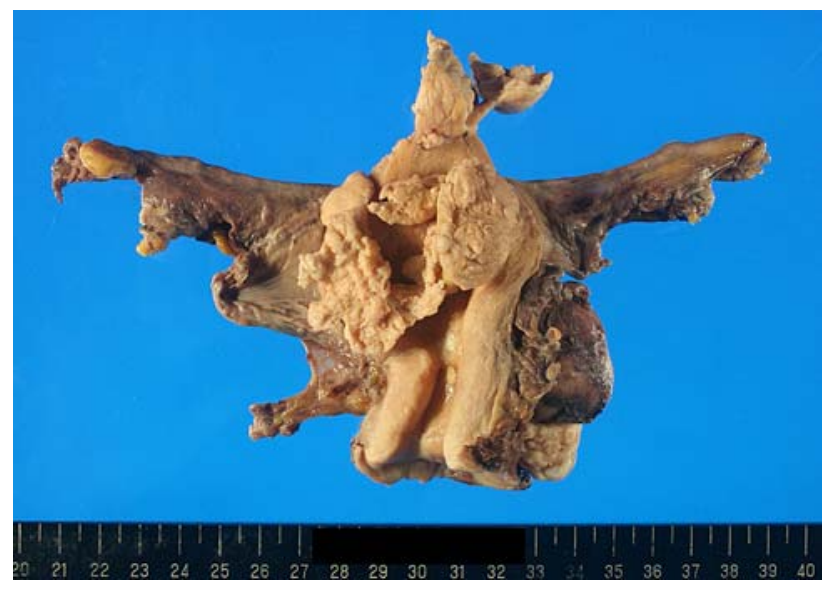

Fig. 1 Endophytic and exophytic growth of a solid mass was found in the uterine body

normal limits. Endometrial biopsy showed malignancy. The FIGO stage of the tumor was clinically diagnosed as stage $\mathrm{Ib}$ endometrial carcinoma, and the patient underwent hysterectomy, bilateral salpingo-oophorectomy, and pelvic lymph node dissection. Ascitic fluid is not found clinically. However, tumor cells are detected by peritoneal wash. The FIGO stage was pathologically diagnosed as stage IIIa.

The patient was treated with chemotherapy (paclitaxel and carboplatin). No recurrence of the tumor was found 5 months after surgery.

\section{Materials and methods}

Histological studies included light microscopic, histochemical, and immunohistochemical examinations. Sections were processed and stained simultaneously for each antibody by the indirect immunoperoxidase method using a manual technique or an automatic immunostainer (Ventana, Tucson, AZ). Envision/HRP kits (DAKO, Carpinteria, CA) were used for detection using the manual technique. As shown in Table 1, ten commercially available antibodies

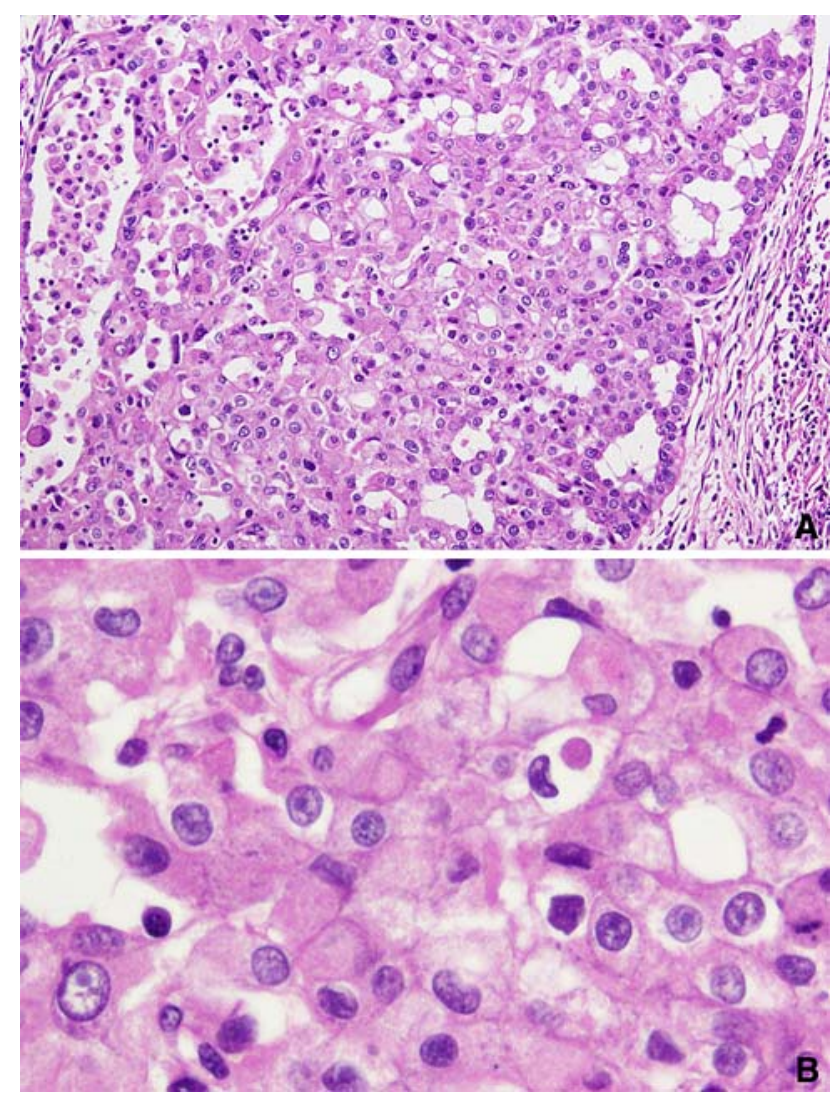

Fig. 2 Pathological findings of the endometrial oncocytic carcinoma. a Low-power view showing areas of solid and papillary architecture. Hematoxylin and eosin, original magnification $\times 20$. b The tumor cells had fine oxiphilic cytoplasm. Hematoxylin and eosin, original magnification $\times 100$

were used in this study to analyze the tumors. These included antimitochondrial antigen (AMA), p53, ER, PgR, GCDFP-15, mammaglobin (MMG), c-erbB-2, TTF-1, thyroglobulin, and Ki-67 antibodies. The results of immunostaining for each antibody were evaluated. When fewer than $50 \%$ cells were positively stained, the results were classified as + and when more than $50 \%$ cells were stained positively they were classified as ++ .
Table 1 Primary antibodies used in immunohistochemistry

\begin{tabular}{lllll}
\hline Antibody & Code or clone & Manufacturer & Dilution & Antigen retrieval \\
\hline AMA & $113-1$ & Biogenex & $1: 50$ & Boiled using citrate buffer/pH 6.0 \\
p53 & DO-7 & Ventana & & Autostainer \\
ER & 6 F11 & Ventana & & Autostainer \\
PgR & 16 & Ventana & & Autostainer \\
GCDFP-15 & D6 & Covance & $1: 50$ & None \\
MMG & 304-1A5 & Dako & $1: 20$ & Boiled using citrate buffer/pH 6.0 \\
c-erbB-2 & PN2A & Dako & $1: 50$ & Boiled using citrate buffer/pH 6.0 \\
TTF-1 & SPT-24 & Novocastra & $1: 50$ & Boiled using citrate buffer/pH 6.0 \\
TG & A0251 & Dako & $1: 100$ & None \\
Ki-67 PI & MIB-1 & Dako & $1: 50$ & Boiled using citrate buffer/pH 6.0 \\
\hline
\end{tabular}




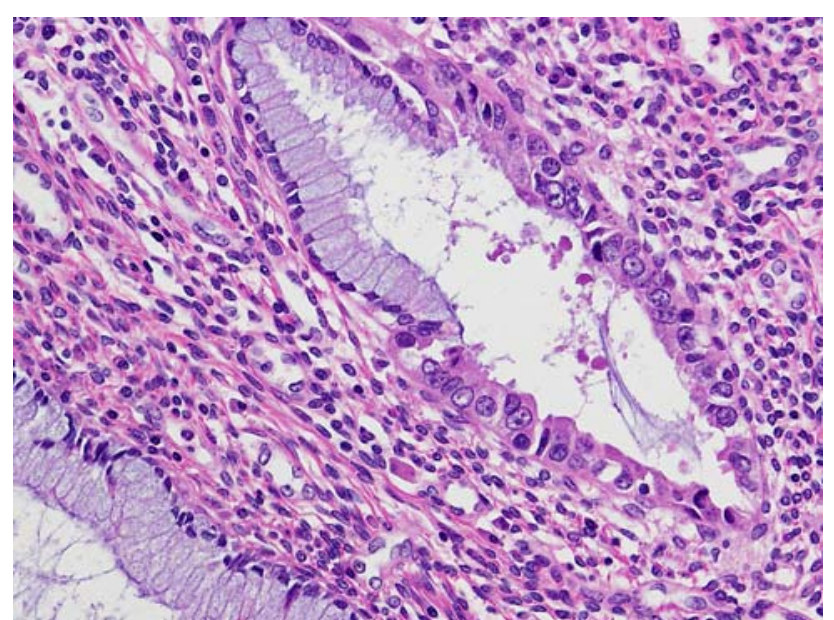

Fig. 3 Intraepithelial extension to the endocervical glands. Hematoxylin and eosin, original magnification $\times 40$

\section{Results}

Macroscopically, the tumor was a whitish solid mass, $5 \mathrm{~cm} \times 6 \mathrm{~cm} \times 4 \mathrm{~cm}$ in size. The tumor was located in the uterine body, focally occupying the cervix (Fig. 1).

Microscopically, the tumor cells were arranged in loose, solid, or solid-tubular nests in a focal papillary manner. Most of the tumor cells possessed abundant oncocytic cytoplasm and enlarged round or oval nuclei with prominent nucleoli (Fig. 2). The tumor invaded more than half of the
Table 2 Immunohistochemical profiles of the present endometrial cancer

\begin{tabular}{ll}
\hline & Positive cell ratio \\
\hline AMA & ++ \\
p53 & ++ \\
ER & - \\
PgR & - \\
GCDFP-15 & - \\
MMG & - \\
c-erbB-2 & - \\
TTF-1 & ++ \\
TG & - \\
Ki-67 PI & $50 \%$ \\
\hline
\end{tabular}

myometrium. Intraepithelial extension to the cervical glands was focally observed (Fig. 3). Oncocytic metaplasia was not found in the non-neoplastic endometrial glands. There was no lymph nodal metastasis.

Immunohistochemistry results revealed that the tumor cells were positive for AMA, p53, and TTF-1 and negative for thyroglobulin, ER, PgR, and GCDFP-15 (Fig. 4).

Immunostainings were performed on the previous breast cancer to confirm whether the tumor was a primarily endometrial oncocytic carcinoma or whether it had metastasized from the breast cancer. Results of immunostainings are summarized in Tables 2 and 3.
Fig. 4 Immunohistochemistry of the endometrial oncocytic carcinoma. a Hematoxylin and eosin, original magnification $\times 40$. b Immunostaining for antimitochondrial antibody showing granular positive reaction in tumor cytoplasm. c Expression of TTF-1 was occasionally observed in tumor nuclei. d Expression of p53 was frequent in tumor nuclei
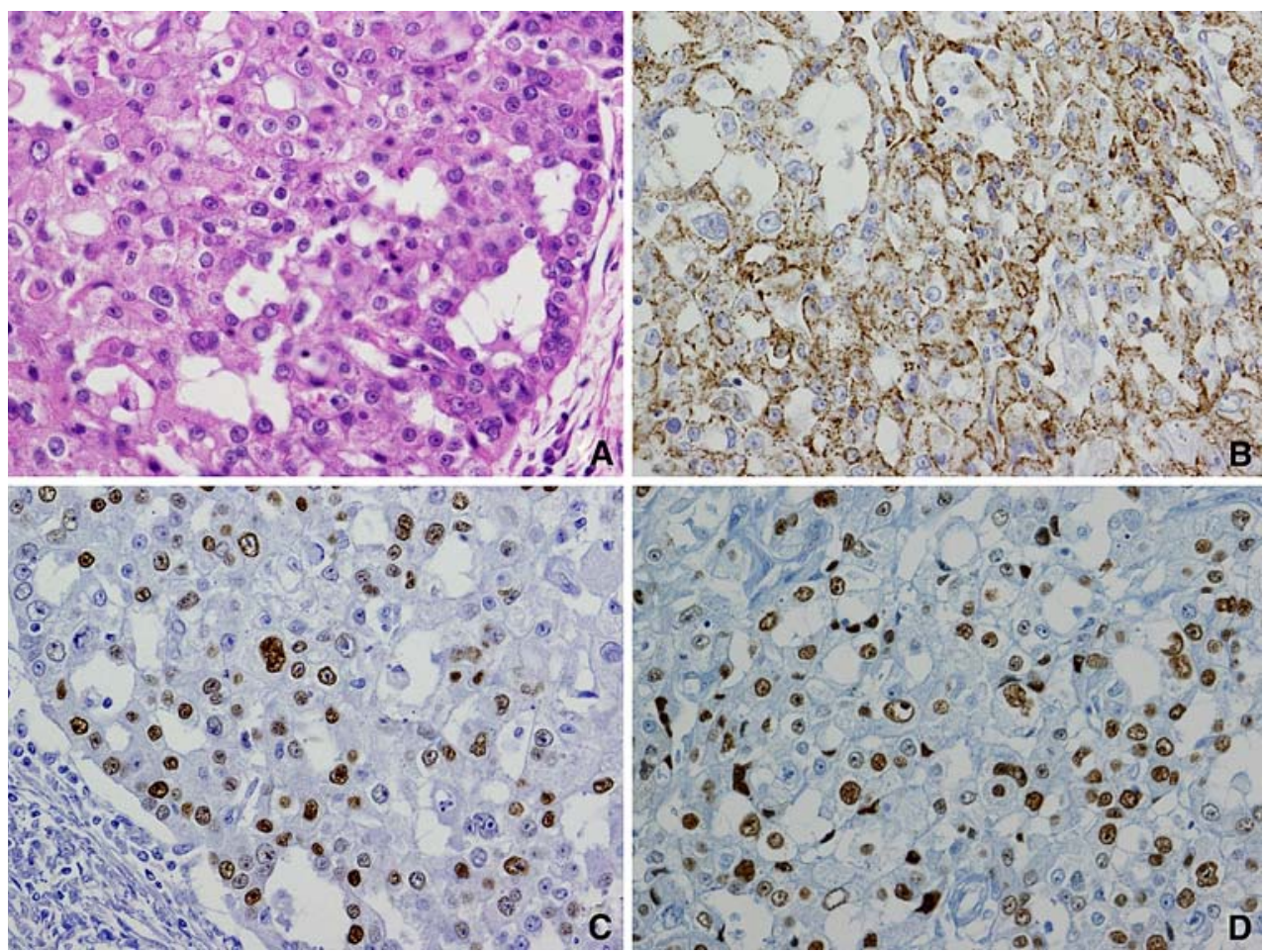
Table 3 Immunohistochemical profiles of the previously operative breast cancer

\begin{tabular}{ll}
\hline & Positive cell ratio \\
\hline AMA & - \\
p53 & - \\
ER & - \\
PgR & - \\
GCDFP-15 & - \\
MMG & - \\
c-erbB-2 & - \\
TTF-1 & - \\
TG & - \\
Ki-67 PI & $50 \%$ \\
\hline
\end{tabular}

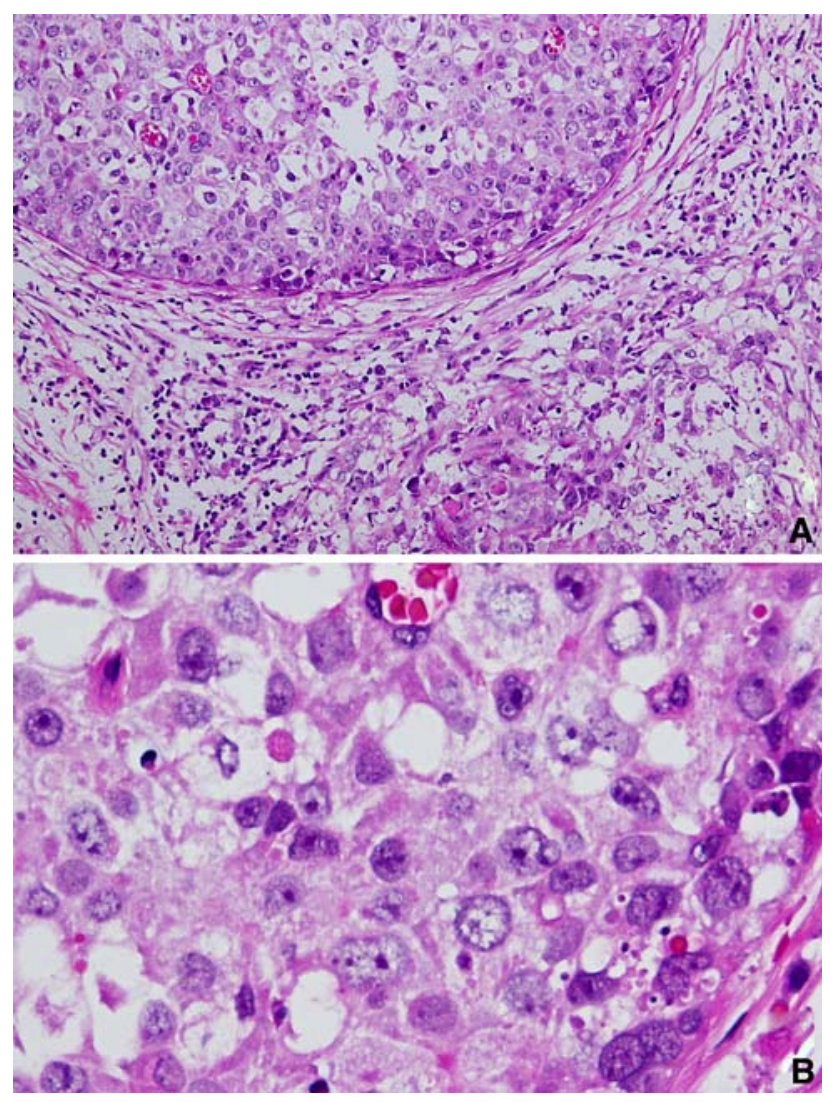

Fig. 5 Pathological findings of previously operated breast carcinoma. a Low-power view showing areas of large solid nest and adjacent invasive small nests. Hematoxylin and eosin, original magnification $\times 20$. b Tumor cells had granular oxiphilic cytoplasm. Hematoxylin and eosin, original magnification $\times 100$

Tumor cells in the breast cancer were arranged in solid nests with stromal invasion, and possessed eosinophilic cytoplasm and enlarged nuclei with prominent nucleoli (Fig. 5). Immunohistochemistry revealed that the tumor cells were negative for AMA, TTF-1, TG, MMG, ER, PgR, and GCDFP- 15 .
When the tumor cells of the endometrial cancer and breast cancer were compared, both were found to possess oxiphilic cytoplasm; however, they had different immunostaining patterns.

The endometrial tumor was diagnosed as primary endometrial oncocytic carcinoma because of the presence of intraepithelial extension to the endocervical glands and immunohistochemical profiles different from those of the breast cancer.

\section{Discussion}

Oncocytic tumors are generally known to contain oxiphilic cytoplasm, and these tumors occur in various organs such as the thyroid, salivary, and adrenal glands, kidney, and breast. However, pure oncocytic carcinoma of the endometrium is very rare [1].

In the clinicopathologic features of oncocytic endometrial carcinoma about the present and reviewed cases, mean of patient age is 67.6 years and the tumor is mainly composed of oncocytic cancer cells, which are arranged in glandular, solid nests in a papillary manner (Table 4) [1].

In general, oncocytic cytoplasm contains many mitochondria or eosinophilic granules [1, 6-9]. Tumor cells in endometrial oncocytic carcinoma contain many mitochondria in the cytoplasm [1]. Commonly occurring breast tumors possess eosinophilic cytoplasm, which contains apocrine or other secretory granules. However, oncocytic breast cancer with numerous cytoplasmic mitochondria has also been reported [10].

In immunohistochemical analyses, oncocytic carcinomas are frequently positive for p53, and rarely positive for ER and PgR [1]. Therefore, these tumors are classified as type 2 endometrial cancers (Table 5).

In the present case, endometrial tumor cells were positive for antimitochondrial antibody and negative for mammaglobin and GCDFP-15. On the other hand, the breast tumor was negative for antimitochondrial antibody. These results indicate that the breast tumor did not contain many mitochondria.

The present tumor was also positive for TTF-1. TTF- 1 is generally expressed in non-neoplastic and neoplastic thyroid and lung tissues. However, TTF-1-positive tumors are rarely reported in other sites. TTF- 1 expression is detected in approximately $20 \%$ of cases of endometrioid adenocarcinoma [3]. However, the relation between TTF-1 and the endometrial glands is unknown. Breast cancers are generally negative for TTF-1 $[11,12]$.

Tamoxifen was used for postoperative chemotherapy in this patient for 1 year. Long-term treatment with tamoxifen frequently induces endometrial cancer. In this case, adju- 
Table 4 Clinicopathologic features, treatment and outcome of the present case and review of the literature

\begin{tabular}{|c|c|c|c|c|c|c|}
\hline & Age & Gross feature & Histologic features & $\begin{array}{l}\text { FIGO } \\
\text { stage } \\
\text { treatment }\end{array}$ & & Outcome (months) \\
\hline $\begin{array}{l}\text { Present } \\
\text { case }\end{array}$ & 80 & 5-cm polypoid mass & $\begin{array}{l}\text { Solid, glandular, focal } \\
\text { papillary }\end{array}$ & IIIa & EMC, TAH-BSO, CT & NED (5) \\
\hline 1 & 66 & 4-cm polypoid mass & Glandular, focal papillary & IIIc & EMC, TAH-BSO, RT & $\begin{array}{l}\text { Omental metastasis (13); } \\
\text { fatal PE (14) }\end{array}$ \\
\hline 2 & 57 & Thickened endometrium & $\begin{array}{l}\text { Solid nests, single cells, } \\
\text { focal papillary }\end{array}$ & $\mathrm{IIb}$ & EMC, TAH-BSO & $\begin{array}{l}\text { Died with widely metastatic } \\
\text { breast carcinoma (6) }\end{array}$ \\
\hline 3 & 65 & $6.5-\mathrm{cm}$ polypoid mass & Papillary & Ic & EMC, TAH-BSO, RT & NED (27) \\
\hline 4 & 70 & $2-\mathrm{cm}$ friable mass & Glandular, focal papillary & $\mathrm{Ib}$ & EMC, TAH-BSO & NED (31) \\
\hline
\end{tabular}

FIGO International Federation of Gynecology and Obstetrics; EMC endometrial curettage; TAH-BSO total abdominal hysterectomy and bilateral salpingo-oophorectomy; $C T$ chemotherapy; $R T$ radiation therapy; $P E$ pulmonary embolus; $N E D$ no evidence of disease

Table 5 Immunohistochemical profiles of oncocytic carcinoma of endometrium in the present case and review of the literature

\begin{tabular}{lll}
\hline & Present case & Review cases [1] \\
\hline AMA & Positive & ND $^{\mathrm{a}}$ \\
p53 & positive & $4 / 4$ \\
ER & negative & $1 / 4$ \\
PgR & negative & $0 / 4$ \\
GCDFP-15 & negative & $0 / 4$ \\
MMG & Negative & $\mathrm{ND}$ \\
c-erbB-2 & Negative & $1 / 4$ \\
TTF-1 & Positive & $\mathrm{ND}$ \\
TG & Negative & $\mathrm{ND}$ \\
Ki-67 PI & $50 \%$ & $14-33 \%$ \\
\hline
\end{tabular}

a Many mitochondria were detected in the ultrastructural study

vant chemotherapy with tamoxifen was used for a short time. Therefore, the risk of endometrial cancer caused by this treatment is low [13].

Breast tumors frequently metastasize to the endometrium [4]. Therefore, endometrial oncocytic carcinoma must be distinguished from metastasis of breast cancers. In general, expression of mammaglobin and GCDFP-15 is important in distinguishing breast cancer from endometrial cancers. However, some breast cancers, such as the present case, are negative for these markers. Immunohistochemistry for antimitochondrial antibody and TTF- 1 is useful to distinguish between endometrial oncocytic carcinoma and endometrial carcinoma metastasized from breast cancer.

Open Access This article is distributed under the terms of the Creative Commons Attribution Noncommercial License which permits any noncommercial use, distribution, and reproduction in any medium, provided the original author(s) and source are credited.

\section{References}

1. Silver SA, Cheung AN, Tavassoli FA (1999) Oncocytic metaplasia and carcinoma of the endometrium: an immunohistochemical and ultrastructural study. Int $\mathbf{J}$ Gynecol Pathol 18:12-19. doi:10.1097/00004347-199901000-00003

2. Kounelis S, Kapranos N, Kouri E, Coppola D, Papadaki H, Jones MW (2000) Immunohistochemical profile of endometrial adenocarcinoma: a study of 61 cases and review of the literature. Mod Pathol 13:379-388. doi:10.1038/modpathol.3880062

3. Siami K, McCluggage WG, Ordonez NG, Euscher ED, Malpica A, Sneige $\mathrm{N}$ et al (2007) Thyroid transcription factor-1 expression in endometrial and endocervical adenocarcinomas. Am J Surg Pathol 31:1759-1763

4. Scopa CD, Aletra C, Lifschitz-Mercer B, Czernobilsky B (2005) Metastases of breast carcinoma to the uterus. Report of two cases, one harboring a primary endometrioid carcinoma, with review of the literature. Gynecol Oncol 96:543-547. doi:10.1016/j.ygyno.2004.09.064

5. Bhargava R, Beriwal S, Dabbs DJ (2007) Mammaglobin vs GCDFP-15: an immunohistologic validation survey for sensitivity and specificity. Am J Clin Pathol 127:103-113. doi:10.1309/ TDP92PQLDE2HLEET

6. Mai KT, Yazdi HM, Boone SA (1995) 'Minimal deviation' endometrioid carcinoma with oncocytic change of the endometrium. Arch Pathol Lab Med 119:751-754

7. Giordano G, Gabrielli M, Gnetti L, Ferri T (2006) Oncocytic carcinoma of parotid gland: a case report with clinical, immunohistochemical and ultrastructural features. World J Surg Oncol 4:54. doi:10.1186/1477-7819-4-54

8. Hoang MP, Ayala AG, Albores-Saavedra J (2002) Oncocytic adrenocortical carcinoma: a morphologic, immunohistochemical and ultrastructural study of four cases. Mod Pathol 15:973-978. doi:10.1038/modpathol.3880638

9. Alexiev B, Boschnakova Z, Prokopanov C (1994) The apocrine carcinoma of the breast. A cytological, immunohistochemical and ultrastructural study of 6 cases. Zentralbl Pathol 140:129-134

10. Damiani S, Eusebi V, Losi L, D’Adda T, Rosai J (1998) Oncocytic carcinoma (malignant oncocytoma) of the breast. Am J Surg Pathol 22:221-230. doi:10.1097/00000478-199802000-00011

11. Harlamert HA, Mira J, Bejarano PA, Baughman RP, Miller MA, Whitsett JA et al (1998) Thyroid transcription factor-1 and cytokeratins 7 and 20 in pulmonary and breast carcinoma. Acta Cytol 42:1382-1388 
12. Bejarano PA, Baughman RP, Biddinger PW, Miller MA, Fenoglio-Preiser C, Al-Kafaji B et al (1996) Surfactant proteins and thyroid transcription factor-1 in pulmonary and breast carcinomas. Mod Pathol 9:445-452

13. Delozier T, Spielmann M, Macé-Lesec'h J, Janvier M, Hill C, Asselain B, Julien JP, Weber B, Mauriac L, Petit JC, Kerbrat P,
Malhaire JP, Vennin P, Leduc B, Namer M (2000) Tamoxifen adjuvant treatment duration in early breast cancer: initial results of a randomized study comparing short-term treatment with long-term treatment. Fédération Nationale des Centres de Lutte Contre le Cancer Breast Group. J Clin Oncol 18:3507-3512 